\title{
Haemophagocytic lymphohistiocytosis in inflammatory bowel disease with virus infection
}

\author{
Yuan $\mathrm{Li}^{1}$, Xuefeng Xia², Jing Zhang ${ }^{1}$, Zhiqiang Song ${ }^{1}$, Liya Zhou ${ }^{1}$, Yaopeng Zhang ${ }^{1}$, Yonghui Huang \\ Yanyan Shi', Eamonn M.M. Quigley ${ }^{2}$, Shigang Ding ${ }^{1}$ \\ 1Department of Gastroenterology, The Third Hospital of Peking University, Beijing, China \\ ${ }^{2}$ Methodist Hospital Research Institute, Weill Cornell School of Medicine, Houston, TX, USA
}

Prz Gastroenterol 2015; 10 (2): 78-82 DOI: $10.5114 /$ pg.2015.48995

Key words: haemophagocytic lymphohistiocytosis, inflammatory bowel disease, cytomegalovirus, Epstein-Barr virus, thiopurines.

Address for correspondence: Prof. Shigang Ding MD, Department of Gastroenterology, Department of Gastroenterology,

The Third Hospital of Peking University, North Garden Road, No 49, Haidian District, Beijing, 100191, China, phone: +86 10 82266925, e-mail: dingshigang222@163.com, leeeyuan@aliyun.com

\begin{abstract}
Patients with inflammatory bowel disease (IBD) are at risk of developing haemophagocytic lymphohistiocytosis (HLH) because of chronic systemic inflammation as well as exposure to immunosuppressive medications. The two main causes of $\mathrm{HLH}$ in IBD patients are infection with cytomegalovirus and Epstein-Barr virus. Patients with Crohn's disease are more susceptible to $\mathrm{HLH}$ than those with ulcerative colitis. The majority of cases are seen in people receiving an immunosuppressive regimen that included thiopurines.
\end{abstract}

\section{Introduction}

Haemophagocytic lymphohistiocytosis (HLH) is a rare and life-threatening condition with complications that can include multiple organ failure. It is caused by dysregulation in natural killer T-cell function, resulting in the activation and proliferation of lymphocytes or histiocytes with uncontrolled haemophagocytosis and cytokine overproduction [1]. HLH2004 is the established treatment guideline for $\mathrm{HLH}$ [2]. The diagnostic guidelines for HLH are shown below (Table I).

HLH-2004 chemo-immunotherapy includes etoposide, dexamethasone, cyclosporine A, and, in selected patients, intrathecal therapy with methotrexate and corticosteroids [3].

There are two main types of HLH: primary and secondary. Primary HLH is inherited in an autosomal recessive or $\mathrm{X}$-linked manner and can be divided into two subgroups: familial HLH and X-linked proliferative syndrome. Secondary HLH has been largely associated with infection and mainly occurs in immunocompromised patients, including those with inflammatory bowel disease (IBD) [1].

\section{Clinical characteristics of haemophagocytic lymphohistiocytosis in inflammatory bowel disease patients}

Secondary HLH may arise from infectious, rheumatologic, malignant, or metabolic conditions. Inflammatory bowel disease (ulcerative colitis (UC) and Crohn's disease (CD)) is often considered an autoimmune disease based on the absence of identifiable causal microorganism(s) and histopathological inflammatory process and response to immune-modulating therapy. The wide spread use of immunosuppressants in patients with IBD increases the risk of infection and subsequently the risk of secondary $\mathrm{HLH}$. A study has shown that paediatric IBD patients are at a 100-fold greater risk for the development of HLH than the general population [4].

Nineteen cases of HLH with IBD were collected by searching in PubMed and ProQuest with the keywords "HLH" and "IBD", with one case from our hospital. Clinical data from the patients are summarised in Table II [5-18].

Most patients (18/20) were less than 45 years old, and their CD : UC ratio was $16: 4$. Of the 20 patients, 
15 received an immunosuppressive regimen consisting of thiopurines, and three patients received only corticosteroids. The effectiveness of the immunosuppressive regimen was described in 8 patients, and among them 7 patients had a clinical response. The interval from prescription of immunosuppressive regimen to the onset of HLH was 3.5 months to 6 years. The two main causes of $\mathrm{HLH}$ in IBD patients were cytomegalovirus (CMV) (in 10/20 cases) and EBV (in 8/20 cases). Five patients died; 3 from Epstein-Barr virus (EBV) infection, 1 from CMV infection, and 1 from an unknown cause.

The most common symptoms of HLH were fever (20/20), fatigue (8/20), and abdominal pain (7/20). Symptoms resembling those of a cold, such as sore throat (5/20), cough (4/20), rhinorrhoea (3/20), headache $(2 / 20)$, and myalgia $(2 / 20)$, were also common. Six patients presented with severe haematochezia

Table II. Clinical data on IBD patients with HLH

\begin{tabular}{|c|c|c|c|c|c|c|c|c|c|c|}
\hline Author & $\begin{array}{c}\text { Case } \\
\text { number }\end{array}$ & Gender & $\begin{array}{c}\text { Age } \\
\text { [years] }\end{array}$ & CD/UC & $\begin{array}{l}\text { History } \\
\text { of IBD }\end{array}$ & $\begin{array}{l}\text { Medication } \\
\text { history }\end{array}$ & $\begin{array}{l}\text { Clinical } \\
\text { efficacy }\end{array}$ & $\begin{array}{l}\text { History of } \\
\text { immuno- } \\
\text { suppressive } \\
\text { regimen } \\
\text { usage }\end{array}$ & $\begin{array}{l}\text { Trigger } \\
\text { factor }\end{array}$ & Outcome \\
\hline Francolla [5] & 1 & $\mathrm{~F}$ & 18 & $C D$ & 3 years & AZA, INF & Y & 3 years & EBV & Recovered \\
\hline Frizgerald [6] & 1 & $\mathrm{~F}$ & 14 & $C D$ & 4 years & AZA & Y & 4 years & EBV & Recovered \\
\hline Koketsu [6] & 1 & M & 35 & UC & 1 year & COR & Y & 1 year & CMV & Recovered \\
\hline Uslu [8] & 1 & M & 11 & $C D$ & 2 years & $A Z A, C O R$ & Y & 2 years & NA & Died \\
\hline N'guyen [9] & 4 & All F & $28-38$ & All CD & $2-5$ years & $\begin{array}{c}\text { AZA } \\
(2 \text { cases }), \\
\text { AZA + INF } \\
(2 \text { cases })\end{array}$ & NA & NA & CMV & $\begin{array}{l}3 \text { cases } \\
\text { recovered, } \\
1 \text { case died }\end{array}$ \\
\hline Narula [10] & 1 & M & 16 & $C D$ & NA & AZA & NA & 8 months & EBV & Recovered \\
\hline van Langenberg [11] & 1 & F & 32 & UC & 2 years & AZA & NA & 2 years & CMV & Recovered \\
\hline Van Langenberg [11] & 1 & M & 22 & $C D$ & 3 years & AZA & NA & 1 year & CMV & Recovered \\
\hline N'guyen [12] & 1 & M & 25 & $C D$ & 6 years & AZA & NA & 3 years & EBV & Died \\
\hline Miquel [13] & 1 & F & 63 & $C D$ & NA & AZA & Y & 4 years & CMV & Recovered \\
\hline Miquel [13] & 1 & M & 23 & $C D$ & NA & AZA, COR & NA & 1 year & CMV & Recovered \\
\hline Kanaji [14] & 1 & M & 25 & UC & 5 years & COR & $\mathrm{N}$ & 5 years & $\begin{array}{c}\text { Acute } \\
\text { pancreatitis } \\
\text { and toxic } \\
\text { megacolon }\end{array}$ & Recovered \\
\hline Posthuma [15] & 1 & M & 19 & $C D$ & 6 years & $A Z A+C O R$ & Y & 6 years & EBV & Died \\
\hline Mun [16] & 1 & $\mathrm{~F}$ & 52 & UC & 3 years & SUL & Y & $\mathrm{N}$ & CMV & Recovered \\
\hline Salado [17] & 1 & M & 24 & $C D$ & 4 months & INF + COR & NA & 4 months & EBV & Recovered \\
\hline Virdis [18] & 1 & M & 19 & $C D$ & 5 years & 6-MP & NA & 5 years & EBV & Recovered \\
\hline Our patient & 1 & $M$ & 44 & $C D$ & 5 months & COR & Y & 3.5 months & EBV & Died \\
\hline
\end{tabular}

F-female, M-male, AZA - azathioprine, 6-MP-6-mercaptopurine, INF-infliximab, COR-corticosteroids, SUL-sulfasalazine, NA - not available, Y-yes, $N-$ no.
Table I. Diagnostic guidelines for HLH (revised) [2]

Diagnosis of HLH can be established if one of either A or B below is fulfilled:

A) Molecular diagnosis HLH.

B) Diagnosis criteria for HLH (5 of 9 below):

1. Fever

2. Splenomegaly

3. Cytopaenia (minimum 2 of 3 lineages in peripheral blood):

- Haemoglobin < $90 \mathrm{~g} / \mathrm{l}$

- Platelets $<100 \times 10^{9} / 1$

- Neutrophils $<1.0 \times 10^{\%} / 1$

4. Hypertriglyceridemia and/or hypofibrinogenaemia:

- Fasting triglycerides $\geq 3.0 \mathrm{mmol} / \mathrm{l}$

- Fibrinogen $\leq 1.5 \mathrm{~g} / \mathrm{l}$

5. Haemophagocytosis in bone narrow, spleen, or lymph nodes 6. No evidence of malignancy

7. Low or absent NK-cell activity*

8. Ferritin $>500 \mu \mathrm{g} / \mathrm{l}^{*}$

9. Soluble $\mathrm{CD} 25 \geq 2,400 \mathrm{U} / \mathrm{ml}^{\star}$

${ }^{*}$ New added diagnostic criteria. 


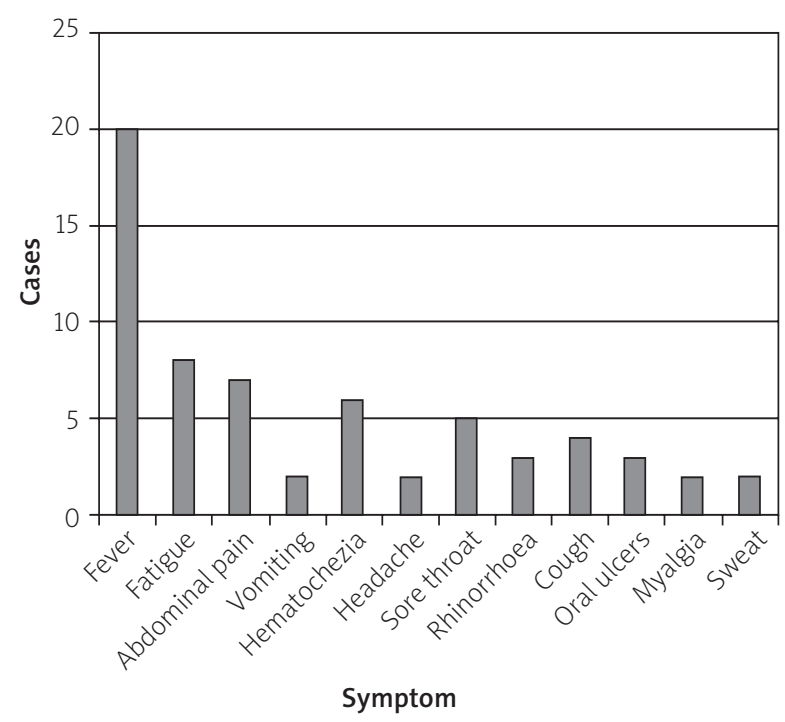

Figure 1. Main symptoms of IBD patients with $\mathrm{HLH}$

(Figure 1). In chest X-rays, 6 patients had multiple bilateral alveolar opacities, and ultrasonography of 2 patients showed multiple hypoechogenic nodules in the spleen or liver.

The cardinal clinical sign and symptom of HLH in IBD patients is persistent fever that is unresponsive to antimicrobials and therefore cannot be explained as infectious. Other signs include hepatosplenomegaly, lymphadenopathy, icterus, uncharacteristic rash, and oedema.

Except for hepatosplenomegaly, some specific features, such as diffuse and low-density lesions in the liver or spleen, can occasionally be found in IBD patients with HLH [1]. In one study the nature of these liver findings was further explored by liver biopsy, which revealed sinusoidal dilation with haemophagocytic histocytosis in all patients [19].

\section{Viral infection is the main triggering factor of haemophagocytic lymphohistiocytosis in inflammatory bowel disease patients}

Virus-infected T lymphocytes undergo clonal proliferation, producing high levels of activating cytokines, including interferon- $\gamma$ (INF- $\gamma$ ), tumour necrosis factor $\alpha$ (TNF- $\alpha$ ), interleukin (IL)-12, and IL-18. The production of these cytokines contributes to macrophage activation and results in haemophagocytosis. Hypercytokinaemia causes cellular damage and dysfunction of multiple organs [20]. Interleukin $1 \beta$ (IL-1 $\beta$ ) elevation increases the level of serum ferritin, which may correlate with disease activity and treatment outcome. Hypertriglyceridaemia is an extremely common finding that is ascribable to lipoprotein lipase inhibition by TNF- $\alpha$.
Both CMV and EBV infections are common in IBD patients. However, infection in an immunocompetent host is usually mild and asymptomatic. The virus can reactivate and lead to systemic infection when the host is immunocompromised.

T-lymphocyte-mediated immune responses drive both IBD-related gut inflammation and control of CMV replication and reactivation [21]. Most researchers believe that CMV infection in UC patients is related to severe colonic mucosal inflammation and refractoriness to conventional therapy and toxic megacolon. Such complications have been reported less frequently in CD patients with CMV infection. Given the possibility of CMV infection, a colonoscopic biopsy must be considered in patients with severe UC who are resistant to steroid therapy. Steroid withdrawal and antiviral therapy may achieve clinical and histological improvement, eliminate the need for surgical treatment, and prevent $\mathrm{HLH}$.

Epstein-Barr virus infection is associated with infectious mononucleosis or $\mathrm{HLH}$, resulting from $\mathrm{CD} 21^{+}$ or CD8 ${ }^{+}$T-cell involvement, respectively. Epstein-Barr virus is the most common cause of overall secondary $\mathrm{HLH}$ due to infections, particularly in eastern Asia [22]. EBV-associated HLH in different diseases tends to have worse outcomes, with significant mortality (literature data reports that mortality were from $25 \%$ to $100 \%$, varying among different surveying groups) [23, 24], as opposed to other infections including CMV infection. Moreover, increased risk of lymphoma in IBD is probably mediated by EBV infection.

\section{Immunosuppressive agents increase opportunistic viral infection in inflammatory bowel disease patients}

Thiopurines are effective in inducing and prolonging remission of IBD. However, they sometimes cause infection. Patients using thiopurine monotherapy have a threefold increased risk of opportunistic infection compared to controls. Combining thiopurines with corticosteroids increases this risk fivefold [25]. The predisposition to viral infections may be due to thiopurine-induced apoptosis of activated T lymphocytes, which are essential in the immunological defence against viruses. Routine clinical practice in monitoring for thiopurine toxicity focuses on total white blood cell count and absolute neutrophil count. Prolonged courses of thiopurines have been documented as resulting in decreased circulating lymphocytes. Lymphopaenia may be important for HLH. Other immunosuppressive agents, such as corticosteroids and infliximab, may also be risk factors for $\mathrm{HLH}$. 


\section{Progress in diagnosis and treatment}

Patients with IBD, particularly those with CD who are receiving thiopurine therapy and who present with 5 days of fever and cervical lymphadenopathy or previous evidence of lymphopaenia, should be screened for HLH. It is of great importance for us to be aware that the phenomenon of haemophagocytosis can also emerge during other diseases, such as sepsis and multiple organ failure [26]. Usually, differential diagnosis is very difficult. Biochemical abnormalities such as elevated ferritin, triglycerides, liver enzymes, and bilirubin, low fibrinogen, aggravation of organomegaly, and cytopaenia are reminiscent of an unusual response to an infectious agent [1]. A recent study supported that CD163, a receptor for haemoglobin-haptoglobin complexes, was a marker for the activation of alternative-pathway scavenger macrophages. The plasma levels of soluble CD163 in $\mathrm{HLH}$ are considerably higher than in other diseases [27]. The combination of SCD25 (produced by activated T cells and dendritic cells) and SCD163 (activated macrophages) may be useful in the diagnosis and follow-up of HLH in IBD patients.

Although mortality due to $\mathrm{HLH}$ is between $95 \%$ and 30-35\%, effective early therapy improves the outcome [28]. Various kinds of primary or secondary infections should be prevented and eliminated before or during the immunosuppressive therapy. Presently, many issues regarding $\mathrm{HLH}$ in IBD patients remain unresolved, and there is no consensus about the optimal treatment. Most researchers believe that thiopurines and anti-TNF monoclonal antibodies should be withdrawn immediately. Antiviral treatment is often effective. Etoposide or even haematopoietic cell transplantation is more effective than steroids alone. Etoposide is especially effective in EBV-associated HLH in IBD patients [10, 17], and its dosage should be adjusted according to the glomerular filtration rate and serum levels of albumin and bilirubin. By specifically targeting and eliminating EBV infected B-cells, rituximab suppresses the immune dysfunction driving the disease process and is often helpful in controlling EBV-associated HLH in IBD patients [6]. Although no lymphoproliferative or malignant conditions secondary to these two drugs have been reported in IBD patients, the side effects should be taken into consideration. Because of the pivotal factor of INF- $\gamma$ in pathogenesis, fontolizumab, a humanised anti-INF- $\gamma$ antibody that is being evaluated in CD, may have the strongest rationale for use in this situation. Monoclonal anti-TNF antibodies should not be used as they may either improve or exacerbate HLH, particularly when the underlying cause is CD. For patients who have recovered from an episode of CMV or EBV infection and $\mathrm{HLH}$, me- salamine, corticosteroids, and even infliximab are considered potentially safer options than thiopurines [29].

\section{Conclusions}

Haemophagocytic lymphohistiocytosis in IBD patients is mainly virus-associated. Thiopurines play a key role in this serious condition. Inflammatory bowel disease patients with pancytopaenia, fever, and splenomegaly should be studied further to rule out HLH. Detection of new gene defects, a better understanding of the complex pathophysiology, and more effective salvage regimens are goals for the future.

\section{Acknowledgments}

The study was supported by a foundation of Chinese Medical Association, Medical Education Branch: No. 2012-JS-59.

\section{Conflict of interest}

The authors declare no conflict of interest.

\section{References}

1. Chandrakasan S, Filipovich AH. Hemophagocytic lymphohistiocytosis: advances in pathophysiology, diagnosis, and treatment. J Pediatr 2013; 163: 1253-9.

2. Jordan MB, Filipovich AH. Hematopoietic cell transplantation for hemophagocytic lymphohistiocytosis: a journey of a thousand miles begins with a single (big) step. Bone Marrow Transplant 2008; 42: 433-7.

3. Henter Jl, Horne A, Aricó M, et al. HLH-2004: Diagnostic and therapeutic guidelines for hemophagocytic lymphohistiocytosis. Pediatr Blood Cancer 2007; 48: 124-31.

4. Egeler RM, Shapiro R, Loechelt B, et al. Characteristic immune abnormalities in hemophagocytic lymphohistiocytosis. J Pediatr Hematol Oncol 1996; 18: 340-5.

5. Francolla KA, Altman A, Sylvester FA. Hemophagocytic syndrome in an adolescent with Crohn disease receiving azathioprine and infliximab. J Pediatr Gastroenterol Nutr 2008; 47: 193-5.

6. Fritzgerald MP, Armstrong L, Hague R, et al. A case of EBV driven haemophagocytic lymphohistiocytosis complicating a teenage Crohn's disease patient on azathioprine, successfully treated with rituximab. J Crohns Colitis 2013; 7: 314-7.

7. Koketsu S, Watanabe T, Hori N, et al. Hemophagocytic syndrome caused by fulminant ulcerative colitis and cytomegalovirus infection: report of a case. Dis Colon Rectum 2004; 47: 1250-3.

8. Uslu N, Demir H, Balta G, et al. Hemophagocytic syndrome in a child with severe Crohn's disease and familial Mediterranean fever. J Crohns Colitis 2010; 4: 341-4.

9. N'Guyen Y, Baumard S, Salmon JH, et al. Cytomegalovirus associated hemophagocytic lymphohistiocytosis in patients suffering from Crohn's disease treated by azathioprine: a series of four cases. Inflamm Bowel Dis 2011; 17: E116-8. 
10. Narula P, Campbell DI, Thomson M, et al. Haemophagocytic lymphohistiocytosis in an adolescent with Crohn's disease on azathioprine. J Crohns Colitis 2009; Suppl 3: 22.

11. van Langenberg DR, Morrison G, Foley A, et al. Cytomegalovirus disease, haemophagocytic syndrome, immunosuppression in patients with IBD: 'a cocktail best avoided, not stirred'. Crohns Colitis 2011; 5: 469-72.

12. Nn'guyen Y, Andreoletti L, Patey M, et al. Fatal Epstein-Barr virus primo infection in a 25-year-old man treated with azathioprine for Crohn's disease. J Clin Microbiol 2009; 47: 1252-4.

13. Miquel T, Bonnet DP, Leport J, et al. Hemophagocytic syndrome in the course of Crohn's disease: possible association with cytomegalovirus infection. Am J Gastroenterol 2009; 104: 252.

14. Kanaji S, Okuma K, Tokumitsu Y, et al. Hemophagocytic syndrome associated with fulminant ulcerative colitis and presumed acute pancreatitis. Am J Gastroenterol 1998; 93: 1956-9.

15. Posthuma EF, Westendorp RG, van der Sluys Veer A, et al. Fatal infectious mononucleosis: a severe complication in the treatment of Crohn's disease with azathioprine. Gut 1995; 36: 311-3.

16. Mun JI, Shin SJ, Yu BH, et al. A case of hemophagocytic syndrome in a patient with fulminant ulcerative colitis superinfected by cytomegalovirus. Korean J Intern Med 2013; 28: 352-5.

17. Salado CT, Gallego AG, Carnerero EL, et al. Hemophagocytic lymphohistiocytosis in Crohn's disease associated with primary infection by Epstein-Barr virus. Inflamm Bowel Dis 2011; 17: E143-4.

18. Virdis F, Tacci S, Messina F, et al. Hemophagocytic lymphohistiocytosis caused by primary Epstein-Barr virus in patient with Crohn's disease. World J Gastrointest Surg 2013; 5: 306-8.

19. de Kerguenec C, Hillaire S, Molinié V, et al. Hepatic manifestations of hemophagocytic syndrome: a study of 30 cases. Am J Gastroenterol 2001; 96: 852-7.

20. Chuang HC, Lay JD, Hsieh WC, et al. Pathogenesis and mechanism of disease progression from hemophagocytic lymphohistiocytosis to Epstein-Barr virus-associated T-cell lymphoma: nuclear factor-kappa B pathway as a potential therapeutic target. Cancer Sci 2007; 98: 1281-7.

21. Monteleone G, Caprioli F. T-cell-directed therapies in inflammatory bowel diseases. Clin Sci (Lond) 2010; 118: 707-15.

22. Ishii E, Ohga S, Imashuku S, et al. Nationwide survey of hemophagocytic lymphohistiocytosis in Japan. Int J Hematol 2007; 86: 58-65.

23. Fisman DN. Hemophagocytic syndromes and infection. Emerg Infect Dis 2000; 6: 601-8.

24. Kasahara Y, Yachie A. Cell type specific infection of Epstein-Barr virus (EBV) in EBV-associated hemophagocytic lymphohistiocytosis and chronic active EBV infection. Crit Rev Oncol Hematol 2002; 44: 283-94.

25. Toruner M, Loftus EV Jr, Harmsen WS, et al. Risk factors for opportunistic infections in patients with inflammatory bowel disease. Gastroenterology 2008; 134: 929-36.

26. Buyse S, Teixeira L, Galicier L, et al. Critical care management of patients with hemophagocytic lymphohistiocytosis. Intensive Care Med 2010; 36: 1695-702.

27. Schaer DJ, Schleiffenbaum B, Kurrer M, et al. Soluble hemoglobin-haptoglobin scavenger receptor CD163 as a lineage-specific marker in the reactive hemophagocytic syndrome. Eur Haematol 2005; 74: 6-10.
28. Filipovich AH. Hemophagocytic lymphohistiocytosis (HLH) and related disorders. Hematology Am Soc Hematol Educ Program 2009; 127-31.

29. Stefanescu C, Allez M, Cadiot G, et al. Hemophagocytic syndrome during inflammatory bowel disease (IBD): a serious and unfamiliar complication of immunosuppressive therapy. J Crohns Colitis 2013; 7: S208-9.

Received: 7.07.2014

Accepted: 28.10 .2014 